\title{
(6) OPEN ACCESS \\ Multiple tobacco product use among US adolescents and young adults
}

\author{
Samir Soneji, ${ }^{1,2}$ James Sargent, ${ }^{1,2}$ Susanne Tanski ${ }^{1}$
}

\begin{abstract}
- Additional material is published online. To view please visit the journal (http:/l dx.doi.org/10.1136/ tobaccocontrol-2014-051638)

${ }^{1}$ Norris Cotton Cancer Center, Geisel School of Medicine at Dartmouth, Lebanon, New Hampshire, USA

${ }^{2}$ Dartmouth Institute for Health Policy \& Clinical Practice, Geisel School of Medicine at Dartmouth, Lebanon, New Hampshire, USA
\end{abstract}

\section{Correspondence to} Dr Samir Soneji, Norris Cotton Cancer Center, Geisel School of Medicine at Dartmouth, One Medical Center Drive, Lebanon, NH 03756, USA;

samir.soneji@dartmouth.edu

Received 24 February 2014 Accepted 13 October 2014

Published Online First

31 October 2014

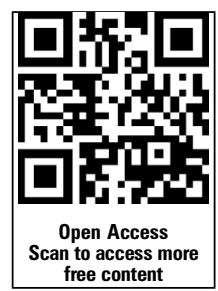

CrossMark

To cite: Soneji S, Sargent J, Tanski S. Tob Control 2016:25:174-180.

\section{ABSTRACT}

Objective To assess the extent to which multiple tobacco product use among adolescents and young adults falls outside current Food and Drug

Administration (FDA) regulatory authority.

Methods We conducted a web-based survey of 1596 16-26-year-olds to assess use of 11 types of tobacco products. We ascertained current (past 30 days) tobacco product use among 927 respondents who ever used tobacco. Combustible tobacco products included cigarettes, cigars (little filtered, cigarillos, premium) and hookah; non-combustible tobacco products included chew, dip, dissolvables, e-cigarettes, snuff and snus. We then fitted an ordinal logistic regression model to assess demographic and behavioural associations with higher levels of current tobacco product use (single, dual and multiple product use).

Results Among 448 current tobacco users, $54 \%$ were single product users, $25 \%$ dual users and $21 \%$ multiple users. The largest single use category was cigarettes $(49 \%)$, followed by hookah (23\%), little filtered cigars $(17 \%)$ and e-cigarettes $(5 \%)$. Most dual and multiple product users smoked cigarettes, along with little filtered cigars, hookah and e-cigarettes. Forty-six per cent of current single, $84 \%$ of dual and $85 \%$ of multiple tobacco product users consumed a tobacco product outside FDA regulatory authority. In multivariable analysis, the adjusted risk of multiple tobacco use was higher for males, first use of a non-combustible tobacco product, high sensation seeking respondents and declined for each additional year of age that tobacco initiation was delayed.

Conclusions Nearly half of current adolescent and young adult tobacco users in this study engaged in dual and multiple tobacco product use; the majority of them used products that fall outside current FDA regulatory authority. This study supports FDA deeming of these products and their incorporation into the national media campaign to address youth tobacco use.

\section{INTRODUCTION}

Many US adolescents and young adults who smoke cigarettes concurrently use alternative tobacco products including cigars and smokeless tobacco. ${ }^{1-6}$ Multiple tobacco use also occurs without cigarette smoking. In 2012, 36\% of past 30-day adolescent tobacco users surveyed in the National Youth Tobacco Survey did not smoke cigarettes at all. ${ }^{7}$ Despite the prominence of alternative tobacco product use, the 2009 Family Smoking and Tobacco Control Act ('Tobacco Control Act') only granted regulatory authority to the Food and Drug Administration (FDA) over cigarettes, loose tobacco and smokeless tobacco while it left other tobacco products outside FDA authority (eg, electronic cigarettes (e-cigarettes) and waterpipe tobacco). Since these other tobacco products are also not covered by the 1998 Master Settlement Agreement (MSA), lack of current FDA regulation gives tobacco companies wide latitude in their ability to target the youth market. ${ }^{8}$ For example, e-cigarette companies began fielding large television advertising campaigns in 2010, something unheard of for cigarettes since the Public Health Cigarette Smoking Act of 1969 banned the practice in 1971. ${ }^{9}$

Adolescents and young adults who use multiple tobacco products may be more susceptible to tobacco advertising and peer tobacco use than their counterparts who never smoked or only smoked cigarettes. ${ }^{1}{ }^{2}$ Multiple tobacco product use may also increase nicotine exposure and nicotine dependence and the risk of other problematic behaviour (eg, binge drinking and marijuana use), compared with sole cigarette smoking. ${ }^{2}{ }^{10}$ Given the risks of multiple tobacco product use, we do not yet know if multiple use includes emerging tobacco products such as dissolvable tobacco, 'e-cigarettes', snus and waterpipe tobacco ('hookah'). We also do not know the demographic and behavioural risk factors for multiple tobacco product use that includes cigarettes and other traditional and emerging tobacco products.

In this study, we seek to fill these research gaps by describing current tobacco use in detail, including chewing tobacco ('chew'), cigarettes, dip and snuff, dissolvables, e-cigarettes, hookah, large or premium cigars, little filtered cigars, medium cigars or cigarillos, and snus in a national and contemporary sample of US adolescents and young adults. We also determine the demographic and behavioural risk factors for multiple tobacco product use among current tobacco users including the age at and type of first tobacco use. Finally, we discuss the regulatory gaps filled and the regulatory gaps that remain open under the FDA 'deeming' proposal (issued in April 2014) for traditional and emerging tobacco products.

\section{METHODS}

\section{Data}

Our data come from the second wave of the Dartmouth Media, Advertising, and Health Study. In wave 1 of the study (Fall 2010-Spring 2011), 3342 15-23-year-olds were recruited from 6466 eligible US households via a random-digit dial telephone survey using landline (67\%) and cell phone (33\%) frames and surveyed using a computerassisted telephone interview. Of the 3342 respondents, 2541 also completed a web-based visual survey at wave 1 . In wave 2 of the study 
(Fall 2012-Spring 2013), we followed the 2541 respondents who completed wave 1 of the study; 1596 completed the webbased visual survey at wave 2 . Participants received US $\$ 25$ for completing wave 2 . The weighted screener response rate using the American Association for Public Opinion Research response rate 3 equalled 63\%. ${ }^{11}$ We observed differential attrition between waves 1 and 2 of the survey; older individuals, non-Hispanic blacks, Hispanics and cigarette smokers were more likely to be lost to follow-up (see web-only table 1). The Dartmouth Committee for the Protection of Human Subjects approved all aspects of the study.

The wave 1 sample was broadly similar to the national population of adolescents and young adults estimated by the 2011 Current Population Survey (CPS) with respect to gender, race/ethnicity and maternal education level (see web-only table 2). The wave 1 sample contained a smaller proportion of young adults (18-23-year-olds) than the national population (69\% in wave 1 vs $75 \%$ nationally). Between waves 1 and 2, racial and ethnic minorities and young adults were more likely to be lost to follow-up than non-Hispanic whites and adolescents, respectively. This differential attrition led to a lower proportion of racial and ethnic minorities and young adults in the wave 2 sample than the national population estimated by the 2013 CPS. The wave 2 sample was broadly representative of the national population with respect to gender and maternal education level.

\section{Outcomes}

We based our assessment of current (past 30 days) multiple tobacco product use on respondents' self-reported answers to the following question, "For each of the tobacco products listed below tell us if you used it in the last 30 days?". The tobacco products included: chewing tobacco ('chew'), cigarettes, dip, dissolvables, e-cigarettes, hookah, large or premium cigars, little filtered cigars, medium cigars or cigarillos, snuff and snus. We recategorised snuff as dip. We defined a 'single user' as a current user of only one tobacco product, a 'dual user' as a current user of two tobacco products and a 'multiple user' as a current user of three or more tobacco products.

\section{Covariates}

We ascertained demographic characteristics of respondents, including age, sex, race and ethnicity (non-Hispanic white, non-Hispanic black, Hispanic and other). We assessed respondents' socioeconomic status through the education level of their mother (less than high school graduate, high school graduate or equivalent, at least some college). We created a composite measure of sensation seeking based on respondents' answers to six personal behaviour topics (eg, "I like to do dangerous things" and "I like new and exciting experiences, even if I have to break the rules," Cronbach's $\alpha=0.72$ ), and categorised the score into quartiles. ${ }^{12}$ We assessed whether any of the respondents' friends smoked cigarettes and parental cigarette smoking status (never, former or current smoker). We classified parental cigarette smoking status as the recent of the two parents' cigarette smoking status. Finally, we ascertained the respondent's age when he or she first tried tobacco, their recollection of the type of tobacco product first tried, and whether it was flavoured (eg, menthol, clove or fruit). We aggregated first product use into combustible or non-combustible and into cigarettes or other tobacco products.

\section{Statistical analyses}

First, we described first tobacco product use and current multiple tobacco product use. We also determine the extent to which multiple tobacco product use falls outside contemporary FDA regulatory authority. Next, we fit a multivariate ordinal logistic regression model on single, dual and multiple tobacco product use among current tobacco users. The model estimates the odds of higher categories of use compared with the odds of lower categories of use (ie, dual vs single and multiple vs dual or single). Model covariates include respondents' age; sex; race/ ethnicity; sensation seeking quartile; the cigarette smoking status of their friends and parents; maternal education; age of tobacco initiation; and whether the first tobacco product was flavoured, combustible or a non-cigarette tobacco product. We assessed the proportionality assumption of the ordinal logistic regression model by performing a likelihood ratio test between the full ordinal logistic regression model and an ordinal logistic regression model that holds a specific covariate (eg, age) as a nominal variable (see web-only table 3 ). We use the ordinal logistic regression model to predict the probabilities of single, dual and multiple tobacco product use varying the age of first tobacco use and setting the value of the other covariates. ${ }^{13}$ Stata V.12.0 and R (R Project for Statistical Computing) V.2.9.2 were used for all statistical analyses.

\section{RESULTS}

\section{Characteristics of never, former and current tobacco users}

Twenty-eight per cent of the sample used at least one tobacco product within the past 30 days $(\mathrm{N}=448)$. Among these current tobacco users, $54 \%$ were single product users, $25 \%$ were dual product users and $21 \%$ were multiple product users (table 1). Compared with non-tobacco users, tobacco users were more commonly male, higher in sensation seeking, and more likely to have friends and parents who smoked. Non-Hispanic blacks were less apt to be tobacco users compared with other racial and ethnic groups.

\section{First tobacco use products among current tobacco users}

Among adolescents, 34\% first tried tobacco between ages 10 and 14 years (early onset) and 66\% first tried tobacco between ages 15 and 17 years (middle onset, table 2). Among young adults, $30 \%$ were early-onset users, $43 \%$ were middle-onset users, and 27\% first tried tobacco between ages 18 and 24 years (late onset). Cigarettes were most often the first-use tobacco product among all age of onset groups followed by dip, hookah and cigars (cigarillos and premium). Use of hookah as the first tobacco product increased with the age of onset: $2 \%$ among early-onset users, 20\% among middle-onset users and 29\% among late-onset users. Late-onset users also more often reported having first used a flavoured tobacco product, a combustible tobacco product and a tobacco product other than cigarettes. For example, $65 \%$ of late-onset users first used a flavoured tobacco product compared with $32 \%$ of early-onset users. First use of smokeless tobacco was uncommon among middle-onset and late-onset users, although dip was a common first-use product among early-onset users (9\%). For all age of onset categories, e-cigarettes were rarely mentioned as a first-use product.

\section{Single, dual and multiple product use among current tobacco users and whether they fall outside current FDA regulatory authority}

Nearly as many single users smoked cigarettes (49\%) as consumed hookah (23\%), little filtered cigars (17\%) and e-cigarettes $(5 \%)$ combined (figure 1). Among the dual product users, the most common pair of products was cigarettes and little filtered cigars $(25 \%)$, followed by cigarettes and hookah $(16 \%)$ and 
Table 1 Demographic and behavioural characteristics of never tobacco users; former tobacco users; and current single, dual and multiple tobacco product users

\begin{tabular}{|c|c|c|c|c|c|}
\hline \multirow[b]{2}{*}{ Characteristic } & \multirow[b]{2}{*}{$\begin{array}{l}\text { Never } \\
\#(\%)\end{array}$} & \multirow[b]{2}{*}{$\begin{array}{l}\text { Former } \\
\#(\%)\end{array}$} & \multicolumn{3}{|l|}{ Current } \\
\hline & & & $\begin{array}{l}\text { Single } \\
\#(\%)\end{array}$ & $\begin{array}{l}\text { Dual } \\
\#(\%)\end{array}$ & $\begin{array}{l}\text { Multiple } \\
\#(\%)\end{array}$ \\
\hline Total & $669(42)$ & $479(30)$ & $241(15)$ & $112(7)$ & 95 (6) \\
\hline \multicolumn{6}{|l|}{ Gender } \\
\hline Female & $364(37)$ & $282(35)$ & $122(19)$ & $40(5)$ & $26(3)$ \\
\hline Male & $305(32)$ & $197(28)$ & $119(19)$ & $72(11)$ & $69(10)$ \\
\hline \multicolumn{6}{|l|}{ Age group, years } \\
\hline $15-17$ & $416(44)$ & $208(29)$ & $94(14)$ & $51(7)$ & $45(6)$ \\
\hline $18-20$ & $161(36)$ & $149(31)$ & $81(17)$ & $38(8)$ & $33(8)$ \\
\hline $21-23$ & $92(24)$ & $122(35)$ & $66(26)$ & $23(9)$ & $17(6)$ \\
\hline \multicolumn{6}{|l|}{ Race/ethnicity } \\
\hline Non-Hispanic white & $494(34)$ & $345(31)$ & $172(18)$ & $86(9)$ & $76(8)$ \\
\hline Non-Hispanic black & $44(45)$ & $31(30)$ & $19(20)$ & $4(4)$ & $2(2)$ \\
\hline Hispanic & $59(29)$ & $53(32)$ & $28(22)$ & $15(10)$ & $9(7)$ \\
\hline Non-Hispanic other & $72(34)$ & $50(34)$ & $22(19)$ & $7(7)$ & $8(7)$ \\
\hline \multicolumn{6}{|c|}{ Sensation seeking quartile } \\
\hline 1st (lowest) & $320(50)$ & $144(28)$ & $61(15)$ & $20(5)$ & $13(2)$ \\
\hline 2nd & $186(37)$ & $126(34)$ & $59(19)$ & $21(4)$ & $15(6)$ \\
\hline 3rd & $108(28)$ & $114(33)$ & $52(22)$ & $27(10)$ & $27(8)$ \\
\hline 4th (highest) & $55(13)$ & $95(31)$ & $69(25)$ & $44(17)$ & $40(13)$ \\
\hline \multicolumn{6}{|l|}{ Friends smoke } \\
\hline No & $255(68)$ & $77(24)$ & $18(6)$ & $5(1)$ & $2(1)$ \\
\hline Yes & $409(26)$ & $400(33)$ & $223(23)$ & $107(10)$ & $93(8)$ \\
\hline \multicolumn{6}{|l|}{ Parents smoke } \\
\hline Never & $427(46)$ & $222(31)$ & $88(11)$ & $40(7)$ & $39(5)$ \\
\hline Former & $115(26)$ & $111(35)$ & $62(23)$ & $28(10)$ & $15(6)$ \\
\hline Current & $119(25)$ & $134(29)$ & $83(29)$ & $40(9)$ & $37(9)$ \\
\hline \multicolumn{6}{|l|}{ Maternal education } \\
\hline $\begin{array}{l}\text { Less than high } \\
\text { school }\end{array}$ & $29(17)$ & $33(27)$ & $22(35)$ & $9(10)$ & $7(10)$ \\
\hline $\begin{array}{l}\text { High school } \\
\text { graduate }\end{array}$ & $103(37)$ & $88(26)$ & $44(23)$ & $26(11)$ & $15(3)$ \\
\hline $\begin{array}{l}\text { At least some } \\
\text { college }\end{array}$ & 499 (36) & $346(34)$ & $162(16)$ & $72(7)$ & $69(7)$ \\
\hline \multicolumn{6}{|c|}{ Age first tried tobacco, years } \\
\hline $10-14$ & $-(-)$ & $84(36)$ & $57(32)$ & $34(17)$ & $41(15)$ \\
\hline $15-17$ & $-(-)$ & $183(43)$ & $110(34)$ & $51(13)$ & $40(11)$ \\
\hline $18-24$ & $-(-)$ & $194(64)$ & $70(23)$ & $24(9)$ & $11(5)$ \\
\hline \multicolumn{6}{|c|}{ First tobacco product flavoured } \\
\hline Not flavoured & $-(-)$ & $150(38)$ & $80(32)$ & $52(18)$ & $44(13)$ \\
\hline Flavoured & $-(-)$ & $221(48)$ & $139(31)$ & $52(11)$ & $43(10)$ \\
\hline \multicolumn{6}{|c|}{ First tobacco product type } \\
\hline Cigarette & $-(-)$ & $263(47)$ & $139(30)$ & $70(15)$ & $46(8)$ \\
\hline $\begin{array}{l}\text { Other tobacco } \\
\text { product }\end{array}$ & $-(-)$ & $204(49)$ & $99(28)$ & $42(9)$ & $49(14)$ \\
\hline \multicolumn{6}{|c|}{ First tobacco product combustible } \\
\hline Not combustible & $-(-)$ & $39(42)$ & $11(15)$ & $9(12)$ & $18(31)$ \\
\hline Combustible & $-(-)$ & $428(48)$ & $227(31)$ & $103(13)$ & $77(8)$ \\
\hline
\end{tabular}

cigarettes and e-cigarettes (13\%). Thus, e-cigarette was the third most common dual use product combined with cigarettes, whereas it was an uncommon first-use product. The remaining $21 \%$ of current tobacco users were multiple tobacco product
Table 2 Characteristics and type of first tobacco product used among current tobacco users by age of first tobacco use (\%)

\begin{tabular}{llll}
\hline First tobacco product used & $\begin{array}{l}\mathbf{1 0 - 1 4} \text { years } \\
\mathbf{( N = 1 3 2 )}\end{array}$ & $\begin{array}{l}\mathbf{1 5 - 1 7} \text { years } \\
\mathbf{( N = 2 0 1 )}\end{array}$ & $\begin{array}{l}\mathbf{1 8 - 2 4} \text { years } \\
(\mathbf{N}=105)\end{array}$ \\
\hline $\begin{array}{llll}\text { Characteristic } \\
\quad \text { Flavoured }\end{array}$ & 32.3 & 59.3 & 64.8 \\
$\quad$ Combustible & 85.6 & 93 & 95.2 \\
$\quad$ OTP & 20.5 & 46.7 & 62.5 \\
Type & & & \\
Cigarettes & 79.5 & 53.3 & 37.5 \\
Snuff & 0.8 & 0 & 1.9 \\
Chewing tobacco & 3.8 & 3 & 0 \\
Dip & 9.1 & 3 & 1.9 \\
Snus & 0.8 & 0.5 & 0 \\
Dissolvables & 0 & 0 & 0 \\
Medium cigars or cigarillos & 1.5 & 11.6 & 10.6 \\
Large or premium cigars & 1.5 & 4.5 & 15.4 \\
Little filtered cigars & 1.5 & 4 & 2.9 \\
Hookah & 1.5 & 19.6 & 28.8 \\
E-cigarettes & 0 & 0.5 & 1 \\
\hline
\end{tabular}

OTP, other tobacco products (ie, not cigarettes).

users. As with dual product users, cigarettes were almost always one component of the set of multiple tobacco products. For example, the modal set of multiple tobacco products was cigarettes, little filtered cigars and e-cigarettes (7\%).

To illustrate the regulatory gaps in contemporary polytobacco use, we coloured the 11 tobacco products according to whether they fell within (green) or outside of (red) current FDA regulatory authority (figure 1 and see web only table 4). Forty-six per cent of single users consumed products outside of FDA authority. Additionally, $84 \%$ of dual users and $85 \%$ of multiple users consumed at least 1 product outside FDA authority.

\section{Statistical model of current multiple product use}

All else equal, the odds of multiple use, compared with dual or single use, were higher for males than females (adjusted proportional OR $(\mathrm{AOR})=1.91 ; 95 \% \mathrm{CI} 1.21$ to 3.03 , table 3 ). The odds of multiple use decreased with later onset of first tobacco use $(\mathrm{AOR}=0.89 ; 95 \% \mathrm{CI} 0.8$ to 0.98$)$. Additionally, the odds of multiple use were higher for those who first used a noncombustible tobacco product than for those who initiated tobacco use with a combustible product $(\mathrm{AOR}=2.36 ; 95 \% \mathrm{CI}$ 1.04 to 5.34). Finally, the odds of multiple use were also higher for those in the third and fourth (highest) sensation seeking quartile compared with those in the first (lowest) quartile $(\mathrm{AOR}=2.2 ; 95 \% \mathrm{CI} 1.15$ to 4.21 and $\mathrm{AOR}=2.02 ; 95 \% \mathrm{CI} 1.1$ to 3.72 , respectively). We did not observe independent significant associations of multiple use with age, race/ethnicity, friends or parental smoking, whether the first-use product was flavoured, or whether the first-use product was a tobacco product other than cigarettes.

To illustrate the population-level implication of our findings, we used the ordinal logistic regression model to predict the probabilities of current single, dual and multiple use varying the age of first tobacco use and setting the value of the other covariates (figure 2). The predicted probability of multiple use steadily decreased with age of first tobacco use. Conversely, the predicted probability of single use steadily increased with age of first tobacco use. For example, the probability of multiple use 
Figure 1 Number and type of tobacco products used among current tobacco users. Green shaded bars represent tobacco products regulated by the Food and Drug Administration (FDA). Red shaded bars represent tobacco products not under FDA regulation. 'Other' includes all combination of tobacco products $<5 \%$ of the number of tobacco products category. The full distribution of types of products by the number of tobacco products currently used shown in web-only table 2. Filt., filtered; E-cig, electronic cigarette.

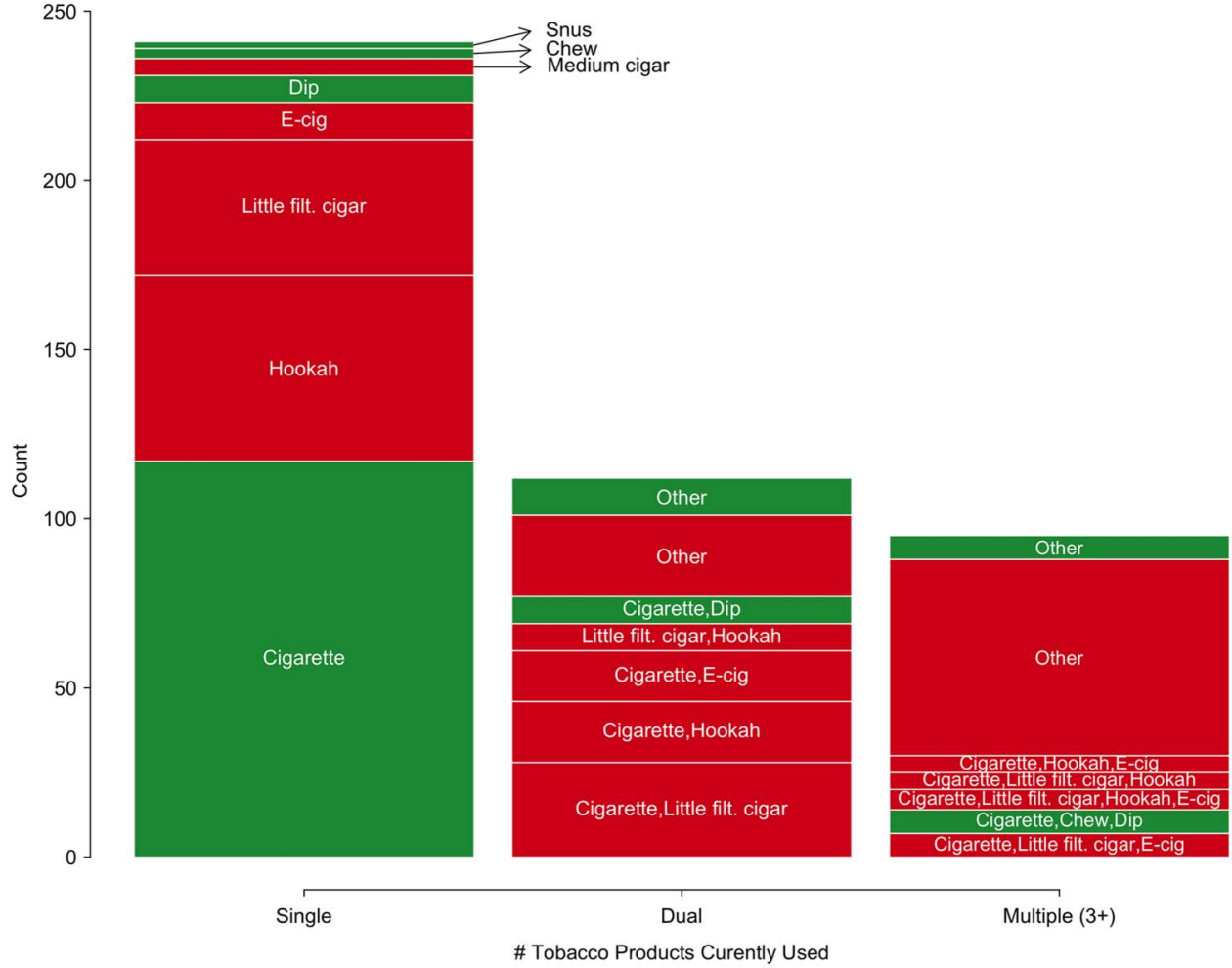

was 25 percentage points higher for those who initiated at age 10 compared with those who initiated at age 18 (95\% CI 0\% to $46 \%$ ). The probability of single use was 28 percentage points lower for those who initiated at age 10 compared with those

Table 3 Multivariable ordinal logistic regression model of demographic and behavioural risk factors for higher categories of current (past 30 days) multiple tobacco product use

\begin{tabular}{|c|c|c|}
\hline Covariate & $\begin{array}{l}\text { Adjusted proportional } \\
\text { OR }\end{array}$ & $95 \% \mathrm{Cl}$ \\
\hline \multicolumn{3}{|l|}{ Age group (Ref: $15-17$ years) } \\
\hline $18-20$ years & 1.67 & 0.84 to 3.31 \\
\hline $21-23$ years & 1.01 & 0.49 to 2.06 \\
\hline Male (Ref: female) & 1.91 & 1.21 to 3.03 \\
\hline \multicolumn{3}{|c|}{ Race/ethnicity (Ref: non-Hispanic white) } \\
\hline Non-Hispanic black & 0.34 & 0.11 to 1.07 \\
\hline Hispanic & 0.9 & 0.43 to 1.89 \\
\hline Non-Hispanic other & 0.99 & 0.46 to 2.11 \\
\hline \multicolumn{3}{|c|}{ Sensation seeking quartile (Ref: 1st (lowest)) } \\
\hline 2nd & 1.18 & 0.6 to 2.31 \\
\hline $3 r d$ & 2.2 & 1.15 to 4.21 \\
\hline 4th (highest) & 2.02 & 1.1 to 3.72 \\
\hline Friends smoke (Ref: no) & 2.14 & 0.74 to 6.22 \\
\hline \multicolumn{3}{|l|}{ Parents smoke (Ref: never) } \\
\hline Former & 0.79 & 0.46 to 1.37 \\
\hline Current & 1.11 & 0.67 to 1.85 \\
\hline \multicolumn{3}{|c|}{ Maternal education (Ref: less than high school) } \\
\hline High school graduate & 1.11 & 0.46 to 2.66 \\
\hline At least some college & 0.84 & 0.38 to 1.89 \\
\hline Age first tried tobacco & 0.89 & 0.8 to 0.98 \\
\hline First tobacco product flavoured & 0.65 & 0.4 to 1.08 \\
\hline $\begin{array}{l}\text { First tobacco product other tobacco } \\
\text { product }\end{array}$ & 1.37 & 0.78 to 2.4 \\
\hline First tobacco product non-combustible & 2.36 & 1.04 to 5.34 \\
\hline
\end{tabular}

Proportional OR estimates adjusted for other covariates in table. who initiated at age 18 (95\% CI 14\% to 44\%). The probability of dual use remained relatively constant across age of first tobacco use.

\section{DISCUSSION}

Our study contributes to a growing body of evidence that finds multiple tobacco product use commonly occurs among

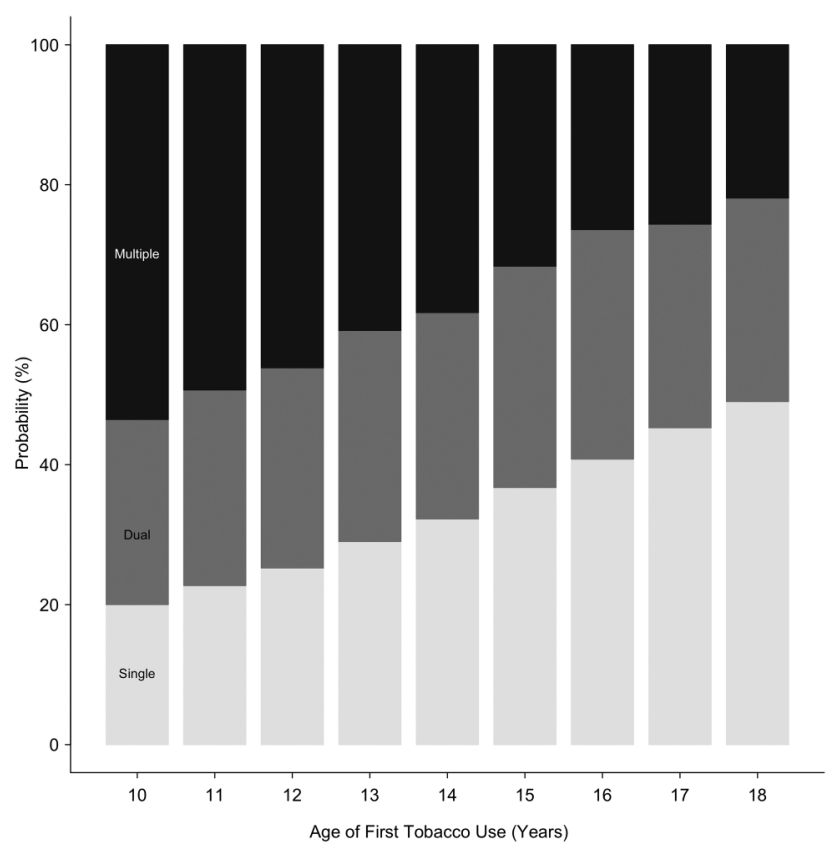

Figure 2 Predicted probabilities of single, dual and multiple tobacco use among current users by age at first tobacco use. Age group set at 18-20 years, sex at male, race/ethnicity at non-Hispanic white, sensation seeking quartile at 2 , friend smoking status at yes, parental smoking status at current, first tobacco product type cigarette and first tobacco product combustible. 
contemporary adolescents and young adults. ${ }^{14-17}$ We demonstrate that current tobacco use spans multiple tobacco products beyond cigarettes. Adolescent and young adult tobacco users widely consume tobacco products outside current FDA regulatory authority, including cigars, hookah and e-cigarettes. We find male adolescents and young adults more often use multiple tobacco products compared with females. We also observe that those who first use tobacco at younger ages are at greater risk of current multiple product use than late-onset users.

Our findings on contemporary tobacco use among adolescents and young adults mirror use among adults. On the basis of the 2012 National Adult Tobacco Survey, Lee et al ${ }^{18}$ found cigars and hookah were the most common tobacco products used after cigarettes among single product users. Cigars and cigarettes, and hookah and cigarettes were the most common pairs of tobacco products used among dual users. Notably, fewer adults reported 30 -day use of e-cigarettes $(0.4 \%$ among single product users and $1.9 \%$ among dual product users (e-cigarettes and cigarettes)) than our findings for adolescents and young adults. Our findings also demonstrate the continued prominence of cigar use among young tobacco users identified in earlier research. 1267

Multiple tobacco product use among adolescents and young adults may promote and reinforce nicotine addiction. The nicotine addiction may then increase the risk of young multiple tobacco product users becoming adult polytobacco users, who postpone tobacco cessation compared with adult single users. ${ }^{19}$ The risks facing adolescent and young adult multiple tobacco product users extend beyond tobacco. Problematic behaviours may cluster because of an underlying tendency to nonconformity or deviance. ${ }^{20}$ Young multiple tobacco product users are also more likely to engage in binge drinking, illicit drug use and excessive gambling. ${ }^{102122}$

The prominence of unregulated tobacco products among adolescents and young adults may be partly due to regulatory gaps in federal and state tobacco laws. Federal law does not require a minimum pack size for little cigars, cigarillos and cigars as it does for cigarettes. Additionally, states tax cigars according to a percentage of the wholesale price, which is less per cigar than the per cigarette excise tax applied to cigarette packs. ${ }^{23}$ Consequently, adolescents and young adults may find the low cost of individually sold cigars appealing because they are more price-sensitive than adult tobacco users. ${ }^{24} 25$ Moreover, federal law does not prohibit free samples of little cigars, cigarillos, or cigars nor does it restrict free samples of hookah tobacco, in contrast to restrictions on cigarettes and smokeless tobacco. Finally, e-cigarettes-the newest class of tobacco products-are not currently subject to any advertising restrictions. The lack of restrictions affords tobacco companies considerable leeway in how they target their advertising and whether they utilise media modalities, such as television, with high exposure to children, adolescents and young adults.

The prominent use of unregulated tobacco products among adolescents and young adults also raises concerns about flavouring. The Tobacco Control Act prohibits the tobacco industry from characterising cigarettes with flavours other than tobacco and menthol. Similar flavouring restrictions do not apply to cigars, e-cigarettes and hookah-products for which flavours abound. Candy-flavoured, fruit-flavoured and liqueur-flavoured tobacco appeal to youth by obscuring the harsh taste of tobacco smoke. ${ }^{26} 27$ In this study, first use of flavoured tobacco products did not significantly increase the probability of current multiple product use. Additional longitudinal research will be needed to determine whether first use of flavoured tobacco products predicts cigarette smoking experimentation and initiation.
Local and state legislation to raise the legal age of tobacco purchase from 18 to 21 years could lower adolescent polytobacco use. In most states,young adults 18 years of age or older are of legal age to purchase tobacco and often serve as the source of cigarettes and other tobacco products to adolescents. $^{28}$ Raising the legal age may reduce the availability of tobacco products to adolescents by reducing their availability to previously age-eligible young adults. ${ }^{29}$ Additionally, raising the legal age of tobacco purchase from 18 to 21 years could lower young adult polytobacco use. The intensity of smoking increases substantially between ages 18 and 21 years and reduced availability of cigarettes may slow the transition from experimentation to regular use. ${ }^{29}$ The potential impact on non-cigarette use remains unclear. Moreover, actually enacting legislation at the state level has proven challenging. ${ }^{30} \mathrm{~A}$ local ordinance in Needham, Massachusetts in 2005, which raised and enforced the minimum sale age demonstrated substantial reductions in youth smoking; a similar ordinance was recently enacted in New York City. ${ }^{31}$

Our study has some limitations, which may affect its internal and external validity. First, we rely on respondents' self-report of specific tobacco usage and their self-report of first product use, both of which may be subject to recall bias. Second, we assessed whether respondents currently used specific products, although we did not ascertain the frequency and quantity of use. Thus, we cannot determine the intensity of use among single, dual and multiple users. Finally, we cannot determine if first-use tobacco products differed by the age of first use because of (1) differences in the prominence of specific products across time (a 'period effect') or (2) differences in the preference of specific products by age (an 'age effect').

Recently, the FDA launched its The Real Cost advertisement campaign aimed at youth aged 12-17 years who are open to cigarette smoking or who already experiment with cigarettes. The campaign aims to prevent youth cigarette smoking; yet it does not address tobacco products being used by half of adolescent and young adult tobacco users in this study. Future FDA advertisement campaigns may need to focus on other combustible tobacco products such as filtered and medium cigars, which are commonly being used. More importantly, future campaigns may need to address potentially reduced-exposure products (eg, e-cigarettes), which have the potential to recruit lower risk adolescents (ie, ones who have internalised messages about the harms of combustible tobacco use) into a lifetime of nicotine consumption.

In April 2014, the FDA released a proposed set of deeming regulations on currently unregulated tobacco products. The first set of options would extend FDA regulatory authority to all tobacco products (excluding tobacco accessories), while the second set of options would additionally exempt premium cigars. The proposed rule may face delays in becoming a final rule because there are no legal deadlines for action in several remaining steps of the FDA rulemaking process. Once the final rule has been published in the Federal Register, tobacco companies may legally contest the final rule as they did in 2010 when the FDA reissued its final rule after enactment of the Tobacco Control Act. ${ }^{32} 33$ Future litigation could delay implementation of the forthcoming final rule. ${ }^{33}$

Even if the FDA finalises the current deeming proposal, important gaps in tobacco regulation will remain. ${ }^{34}$ The proposed regulation does not restrict the advertising and marketing of newly covered tobacco products (eg, brand and trade name sponsorship of sporting and cultural events), as was stipulated for cigarettes under the MSA. The proposed regulation also does not 
restrict flavours in, and does not establish a minimum pack size, for the newly covered tobacco products (eg, e-cigarettes). Additionally, the FDA does not propose regulatory authority over all components, parts and accessories of e-cigarettes. Without comprehensive regulation of e-cigarettes, adolescents can readily purchase non-nicotine e-cigarettes, many of which freely interchange with parts and cartridges from nicotinecontaining e-cigarettes. Finally, the second option of the proposed rule exempts regulation of premium cigars, which is not justified under the public health standard established under the Tobacco Control Act. ${ }^{34}$ Yet even if future FDA rules cover these regulatory gaps, tobacco regulation extends beyond the FDA. For example, local, state and the federal government levy excise taxes on tobacco. Raising the price of tobacco products through higher taxes may reduce tobacco use among adolescents and young adults, who are more price-sensitive than adults. $^{35}$

In summary, the Tobacco Control Act granted the FDA regulatory authority over cigarettes, smokeless tobacco and roll-your-own tobacco but left regulatory gaps in many other tobacco products widely consumed by adolescent and young adult tobacco users. FDA's efforts to expand its regulatory authority over characteristics of tobacco (eg, menthol flavouring) and other tobacco products (eg, e-cigarettes) will almost certainly face legal challenge by the tobacco industry. The US tobacco control policy may become incongruous with adolescent and young adult tobacco use as these populations increasingly consume tobacco products other than cigarettes, with or without concurrent cigarette smoking, that fall outside of FDA regulatory authority.

\section{What this paper adds}

What is already known on this subject

- Many US adolescents and young adults who smoke cigarettes concurrently use alternative tobacco products including cigars and smokeless tobacco.

- Multiple tobacco use also occurs without cigarette smoking.

What important gaps in knowledge exist on this topic

-We do not yet know if multiple tobacco product use includes emerging tobacco products such as dissolvable tobacco, electronic cigarettes, snus and waterpipe tobacco.

- We also do not yet know the extent to which multiple tobacco product use among adolescents and young adults falls outside current Food and Drug Administration (FDA) regulatory authority.

What this study adds

- Results of this study show nearly half of current adolescent and young adult tobacco users engaged in dual and multiple tobacco product use; the majority of them used products that fall outside current FDA regulatory authority.

Acknowledgements The authors thank Cathy Backinger, Corinne Husten, Desmond Jenson, Shila Soneji and three anonymous reviewers for helpful comments and suggestions.

Contributors ST and JS designed the survey and acquired the survey data. SS, JS and ST analysed and interpreted the data, drafted the work, approved the final draft and agree to be accountable for all aspects of the work.
Funding This work was supported by the National Cancer Institute grant number CA077026 and the National Center For Advancing Translational Sciences grant number KL2TR001088.

Competing interests None.

Ethics approval Dartmouth Committee for the Protection of Human Subjects.

Provenance and peer review Not commissioned; externally peer reviewed.

Open Access This is an Open Access article distributed in accordance with the Creative Commons Attribution Non Commercial (CC BY-NC 4.0) license, which permits others to distribute, remix, adapt, build upon this work non-commercially, and license their derivative works on different terms, provided the original work is properly cited and the use is non-commercial. See: http://creativecommons.org/ licenses/by-nc/4.0/

\section{REFERENCES}

1 Gilpin EA, Pierce JP. Concurrent use of tobacco products by California adolescents. Prev Med 2003;36:575-84

2 Bombard JM, Rock VJ, Pederson LL, et al. Monitoring polytobacco use among adolescents: do cigarette smokers use other forms of tobacco? Nicotine Tob Res 2008; 10:1581-9.

3 Nasim A, Khader Y, Blank MD, et al. Trends in alternative tobacco use among light, moderate, and heavy smokers in adolescence, 1999-2009. Addict Behav 2012;37:866-70

4 U.S. Department of Health and Human Services. Preventing tobacco use among youth and young adults: a report of the surgeon general. Atlanta, GA: U.S. Department of Health and Human Services, Centers for Disease Control and Prevention, National Center for Chronic Disease Prevention and Health Promotion, Office on Smoking and Health, 2012.

5 Agaku IT, Ayo-Yusuf OA, Vardavas $\mathrm{Cl}$, et al. Use of conventional and novel smokeless tobacco products among US adolescents. Pediatrics 2013;132:e578-86.

6 Schuster RM, Hertel AW, Mermelstein R. Cigar, cigarillo, and little cigar use among current cigarette-smoking adolescents. Nicotine Tob Res 2013;15:925-31.

7 Arrazola RA, Kuiper NM, Dube SR. Patterns of current use of tobacco products among U.S. High school students for 2000-2012-findings from the National Youth Tobacco Survey. J Adolesc Health 2014;54:54-60.

8 Zeller M. Three years later: an assessment of the implementation of the Family Smoking Prevention and Tobacco Control Act. Tob Control 2012;21: 453-4.

9 Public Health Cigarette Smoking Act of 1969.; 91 U.S.C. § 222, 1970.

10 Cavazos-Rehg PA, Krauss MJ, Spitznagel EL, et al. Youth tobacco use type and associations with substance use disorders. Addiction 2014;109:1371-80.

11 The American Association for Public Opinion Research. Standard definitions: final dispositions of case codes and outcome rates for surveys. AAPOR; 2009.

12 Sargent JD, Tanski S, Stoolmiller M, et al. Using sensation seeking to target adolescents for substance use interventions. Addiction 2010; 105:506-14.

13 Imai K, King G, Lau O. ologit: Ordinal Logistic Regression for Ordered Categorical Dependent Variables. In: Zelig: Everyone's Statistical Software.; 2007. http://gking. harvard.edu/zelig

14 Rath JM, Villanti AC, Abrams DB, et al. Patterns of tobacco use and dual use in US young adults: the missing link between youth prevention and adult cessation. J Environ Public Health 2012;2012:1-9.

15 Richardson A, Rath J, Ganz 0, et al. Primary and dual users of little cigars/cigarillos and large cigars: demographic and tobacco use profiles. Nicotine Tob Res 2013;15:1729-36.

16 Richardson A, Williams V, Rath J, et al. The next generation of users: prevalence and longitudinal patterns of tobacco use among US young adults. Am J Public Health 2014;104:1429-36.

17 Wang B, King BA, Corey CG, et al. Awareness and use of non-conventional tobacco products among U.S. students, 2012. Am J Prev Med 2014;47(2 Suppl 1): S36-52.

18 Lee YO, Hebert CJ, Nonnemaker JM, et al. Multiple tobacco product use among adults in the United States: cigarettes, cigars, electronic cigarettes, hookah, smokeless tobacco, and snus. Prev Med 2014;62:14-19.

19 Henningfield JE, Rose CA, Giovino GA. Brave new world of tobacco disease prevention: promoting dual tobacco-product use? Am J Prev Med 2002;23: 226-8.

20 Jessor R. Problem-behavior theory, psychosocial development, and adolescent problem drinking. Br J Addict 1987:82:331-42.

21 Wetter DW, McClure JB, de Moor C, et al. Concomitant use of cigarettes and smokeless tobacco: prevalence, correlates, and predictors of tobacco cessation. Prev Med 2002;34:638-48.

22 Kram Y, Klesges RC, Ebbert JO, et al. Dual tobacco user subtypes in the U.S. air force: dependence, attitudes, and other correlates of use. Nicotine Tob Res 2014; 16:1216-23. 
23 Tobacco Control Legal Consortium. Regulatory options for little cigars. Saint Paul, MN: Public Health Law Center, 2013.

24 Ding A. Youth are more sensitive to price changes in cigarettes than adults. Yale J Biol Med 2003;76:115-24.

25 Franz GA. Price effects on the smoking behaviour of adult age groups. Public Health 2008:122:1343-8.

26 Wayne G, Connolly G. How cigarette design can affect youth initiation into smoking: Camel cigarettes 1983-93. Tob Control 2002;11(Suppl 1):i32-9.

27 Carpenter CM, Wayne GF, Pauly JL, et al. New cigarette brands with flavors that appeal to youth: tobacco marketing strategies. Health Aff (Millwood) 2005;24:1601-10.

28 DiFranza JR, Coleman M. Sources of tobacco for youths in communities with strong enforcement of youth access laws. Tob Control 2001;10:323-8.

29 Steinberg MB, Delnevo CD. Increasing the "smoking age": the right thing to do. Ann Intern Med 2013;159:558-9.
30 Paul Koretz. Tobacco products: minimum legal age: advertising, display, and distribution limitations. http://www.legislature.ca.gov/cgi-bin/port-postquery?bill_ number $=a b \_221$ \&sess $=0304$ \&house $=B$ \&author $=$ koretz .

31 The New York City Department of Health and Mental Hygiene. Tobacco 21; 2013. http://www.nyc.gov/html/doh/downloads/pdf/smoke/tobacco21.pdf

32 Redhead CS, Garvey T. FDA final rule restricting the sale and distribution of cigarettes and smokeless tobacco. Congressional Research Service, 2010.

33 Tobacco Control Legal Consortium. A deeming regulation: what is possible under the law. Saint Paul, MN: Public Health Law Center, 2014.

34 Tobacco Control Legal Consortium. Consortium's comments to FDA on proposed deeming regulation. Saint Paul, MN: Public Health Law Center, 2014.

35 Liang L, Chaloupka F, Nichter M, et al. Prices, policies and youth smoking, May 2001. Addiction 2003;98:105-22. 